\title{
Autonomía territorial y competencias municipales: el pacto local autonómico, con especial referencia a la región de Murcia
}

\author{
José Antonio López Pellicer \\ Profesor Titular de Derecho Administrativo \\ Universidad de Murcia
}

SUMARIO: I. PLANTEAMIENTO. II. LOS ENTES LOCALES EN EL ESTATUTO DE AUTONOMÍA Y EN LA LEGISLACIÓN AUTONÓMICA DE LA REGIÓN DE MURCIA. III. FUNDAMENTOS DEL PACTO LOCAL AUTONÓMICO: DESCENTRALIZACIÓN, AUTONOMÍA, SUBSIDIARIEDAD Y EFICACIA ADMINISTRATIVA. EL PRINCIPIO DE IGUALDAD. IV. COMPETENCIAS AUTONÓMICAS EN MATERIAS DE INTERÉS LOCAL, CON ESPECIAL REFERENCIA A LA COMUNIDAD AUTÓNOMA DE LA REGIÓN DE MURCIA. 1. Urbanismo. 2. Educación. 3. Sanidad 4. Medio ambiente. 5. Servicios sociales. 6. Consumo. 7. Deportes. IV. MODOS DE ARTICULACIÓN JURÍDICA DEL PACTO LOCAL AUTONÓMICO. 1. Técnicas jurídicas utilizables para efectuar la cesión y ejercicio de competencias autonómicas a los municipios. 2. Forma de encauzar el proceso de negociación y acuerdo del hipotético pacto local.

\section{PLANTEAMIENTO}

La Constitución española de 1978 ha establecido un nuevo sistema de reparto territorial del poder público que configura al Estado español como un Estado profundamente descentralizado. A partir de la proclamación constitucional de la «autonomía de las nacionalidades y regiones», que reconocen los artículos 2 y 137 del texto fundamental, y la construcción del «Estado de las Autonomías», que ha ampliado la tradicional estructura territorial del Estado con un nuevo escalón político-administrativo, las Comunidades Autónomas, se ha suscitado una compleja y profunda problemática sobre el reparto de competencias en relación con los entes territoriales preexistentes, esto es, de un lado, respecto del Estado y, de otro, las Corporaciones locales. Y es al legislador, no sólo el estatal, sino también ahora el autonómico, a quienes corresponde establecer, en el marco de la Constitución y de los correspondientes Estatutos de Autonomía, cuáles han de ser las funciones de las distintas Administraciones públicas territoriales,

Abreviaturas que se utilizan:

LBRL: Ley 7/1985, de 2 de abril, de bases del régimen local.

EARM: Estatuto de Autonomía de la Región de Murcia, aprobado por la Ley Orgánica 4/1982, de 9 de junio (modificado por las LO 4/1994, 34/1997 y 1/1998). 
pero sin que la intervención del legislador — estatal y autonómico- pueda dejar a ninguna de éstas, ni por ende a la local, sin facultades suficientes para poder servir a los intereses cuya gestión les corresponde, según ha considerado una constante jurisprudencia constitucional ${ }^{1}$.

Es ya tópico, aunque no por ello menos cierto, afirmar que, de los tres niveles territoriales de poder público que constituyen la organización institucional del Estado autonómico diseñado por la Constitución, la transferencia de funciones y poderes propios, en suma de competencias, se ha producido con especial intensidad en el escalón regional, con la creación de las Comunidades Autónomas. El proceso descentralizador no ha operado, sin embargo, con el necesario contenido y alcance en el ámbito local, a pesar de la naturaleza e importancia de las funciones que tradicionalmente han tenido a su cargo y desempeñado las autoridades locales y, básicamente, los municipios. Que aún siga planteada la «cuestión local» supone por ello que el proceso de reparto y descentralización territorial del poder aún no se ha cumplido ni resuelto de modo satisfactorio en el concreto ámbito donde los ciudadanos experimentan de modo más inmediato sus intereses y necesidades comunes.

Pues bien, para dar respuesta a este problema, se ha propuesto lo que se ha dado en denominar «segunda descentralización», para impulsar y fortalecer el papel de las entidades locales, de modo que el proceso de estructuración pública territorial iniciado con la institucionalización de los entes autonómicos en una, digamos, «primera» descentralización — de superior calado, político, y con poderes incluso legislativos ésta-, se complete con la potenciación y reforzamiento, ahora, de los poderes locales. Lo cual es debido: por un lado, a la circunstancia de que la autonomía protagonizada por las Comunidades Autónomas, respecto del Estado, haya recaído sobre amplios ámbitos materiales de competencias coincidentes en gran parte en las mismas materias sobre las cuales recaían antes las municipales; y a que, por otro lado, la autonomía de los municipios - para poder llevar a cabo la gestión de su ámbito propio de intereses, que la Constitución les reconoce (artículos 137 y 140)— no vaya acompañada en el propio texto constitucional de un contenido competencial propio, a diferencia de lo que sucede con las Comunidades Autónomas; de modo que, como ha advertido la doctrina (Sosa Wagner, Santamaría Pastor), es difícil imaginar la existencia de materias todavía «libres», que quepa atribuir a otras entidades territoriales como los municipios, dada la virtualidad agotadora que ha

\footnotetext{
${ }^{1}$ Ss. TC 4/1981, de 2 de febrero; 32/1981, de 28 de julio; 27/1987, de 27 de febrero; y 214/1989, de 21 de diciembre.
} 
tenido el reparto de competencias efectuado entre el Estado y las Comunidades Autónomas ${ }^{2}$.

La organización administrativa local y, básicamente, la municipal, ha venido así pospuesta ante la propia de las Comunidades Autónomas. Por lo pronto, desde que todas éstas se constituyen e institucionalizan en virtud de sus respectivos Estatutos de Autonomía, con un determinado y sustantivo ámbito competencial — con amplitud mayor o menor según las materias-, ha de transcurrir más de un bienio. Es en 1985 cuando, en efecto, se aprueba la LBRL, que establece la normativa básica del régimen local; normativa ésta que supone un ámbito competencial de los municipios — con relación a las respectivas regulaciones legales sectoriales-, y establece una relación de materias en las cuales el principio-derecho de autonomía local obliga a las Comunidades Autónomas, y no sólo al Esta$\mathrm{do}^{3}$, a regular y atribuir a aquéllos competencias en cada una de las materias que la referida Ley básica estatal relaciona —en su artículo 25-; de modo que los municipios han de recibir las competencias necesarias que les permitan atender y satisfacer sus propios intereses. No cabe desconocer por ello, respecto a las materias en que las Comunidades Autónomas han asumido constitucional y estatutariamente competencias, y en cuyas

\footnotetext{
${ }^{2}$ Ha dicho, por ello, Santamaría Pastor, con gracejo no exento de realismo, que a la mesa donde se sirve la «tarta competencial», podríamos decir gráficamente, se sientan tres comensales con iguales derechos, pero sólo dos disponen de cubiertos, y son ellos los que han de servirse primero: si se tiene en cuenta que estos comensales privilegiados gozan de un excelente apetito y que la cortesía no juega un papel en el banquete, es más que previsible que el tercer invitado tenga que ayunar (Fundamentos de Derecho Administrativo, Edit. Centro Ramón Areces, Madrid, 1991, p. 1121).

${ }^{3}$ Éste, tras un proceso de negociación del Ejecutivo - a través del Ministerio de Administraciones Públicas - y la FEMP, que culmina con la firma de un acuerdo entre ambos (21 de mayo de 1996), donde se concreta el llamado Pacto Local, ha llevado a cabo la reforma de diversos aspectos del régimen local, entre los que destacan: la defensa de la autonomía local ante el Tribunal Constitucional, que no supone un acceso generalizado de las Corporaciones locales a este Tribunal, pero que permite a una mayoría cualificada de municipios y provincias afectadas defender ante el supremo intérprete de la Constitución la garantía institucional de la autonomía local frente a disposiciones estatales o autonómicas que se considere lesionen de modo directo su autonomía; la gobernabilidad, con una nueva regulación de la moción de censura en el ámbito local, introduciendo la convocatoria automática del pleno que ha de discutirla; y la revisión de determinados elementos que contribuyan a la mejora del gobierno local, como la introducción de la cuestión de confianza vinculada a un proyecto concreto, la revisión de procedimientos revestidos de un carácter específicamente local, y la distribución de competencias entre los órganos de gobierno, señaladamente entre el alcalde y el pleno de la Corporación local. (J. RodRíguez-Arana MuÑoz: «El fortalecimiento del poder local», en Actualidad Administrativa n. ${ }^{\circ}$ 3/2000, pp. 97-92). Sobre el Pacto Local y sus antecedentes, vid. asimismo A. IgLesias Martín: Autonomía municipal, descentralización política e integración europea de las Entidades Locales, Edit. Ariel, Barcelona, 2002 (pp. 153 y sgs.).; y F. García Rubio: El Pacto Local, inédito (de próxima publicación por el Centro de Estudios Políticos y Constitucionales).
} 
materias están presentes intereses locales, que es a éstas a quienes incumbe completar el proceso de descentralización territorial, en lo local.

Al no agotarse, por ello, con el ámbito estatal, el proceso descentralizador efectuado, mediante el llamado Pacto Local, en la relación Estado-Entes locales, es indudable que la complitud y efectividad de aquél exigía, y exige por ello, para poder completar el proceso de transferencias a favor de éstas, su proyección también al ámbito competencial de cada Comunidad Autónoma, respecto de los entes locales situados en su territorio. Se ha considerado a este objeto que la semejanza entre la tradicional delimitación de la esfera de competencia municipal y las materias acotadas como ámbito competencial de las Comunidades Autónomas, hace hoy del legislador autonómico «el principal definidor de competencias locales» ${ }^{4}$; y por ello mismo, que si las Comunidades Autónomas no abren un proceso subsiguiente de negociación con las entidades locales de su territorio, las expectativas que éstas han depositado en el proceso del pacto local se verían parcialmente defraudadas ${ }^{5}$; y que de poco serviría el pacto local si el movimiento descentralizador no se produce también en el nivel autonómico ${ }^{6}$.

Dado el amplio ámbito de competencias que las Comunidades Autónomas han asumido en sus Estatutos de Autonomía y que afectan al régimen local, estas afirmaciones parecen indudables, y cabalmente por ello ya se ha iniciado en varias Comunidades (Andalucía, Aragón, Asturias, Canarias, Cantabria, Castilla y León, Cataluña, Galicia, La Rioja, Madrid, y la Comunidad Valenciana) el correspondiente proceso que, presumiblemente, habrá de culminar en el correspondiente pacto local autonómico.

Por lo que se refiere en especial a la Región de Murcia, en un documento de «propuestas iniciales para la negociación del pacto local» en el ámbito de ésta, formulado por la Federación de Municipios regional (14 de mayo de 2001), se reitera la formulación hecha por la Comisión Ejecutiva de la propia Federación en su reunión de 16 de noviembre de 2000, de iniciar las actuaciones correspondientes con relación a las competencias propias de la Comunidad Autónoma y que, concretamente, se refieren a las materias de urbanismo, educación, sanidad, servicios sociales, consumo, cultura, medio ambiente y deportes. Y en cuanto a la estrategia a seguir, se

\footnotetext{
${ }^{4}$ L. Parejo Alfonso: «Estado autonómico y régimen local», en Revista Andaluza de Administración Pública, n. 42 (2001), p. 26.

5 J. RodrígueZ-Arana, cit., p. 101.

${ }^{6}$ R. Rivero Ortega: «Autonomía local y competencias: Castilla y León en el escenario previo al Pacto Local», Rev. de Estudios de Administración Local, n. ${ }^{\circ}$ 286-287 (2001), p. 120.
} 
dice que, aunque el pacto local se contempla como un todo unitario, la negociación del mismo ha de abordarse de forma fraccionada, por fases, en las que la negociación se centre sobre determinadas materias -inicialmente sobre urbanismo y educación - y la financiación del gasto que ocasionen las competencias que se transfieran o deleguen.

\section{LOS ENTES LOCALES EN EL ESTATUTO DE AUTONOMÍA Y EN LA LEGISLACIÓN AUTONÓMICA DE LA REGIÓN DE MURCIA}

En la norma institucional que constituye el Estatuto de Autonomía de la Región de Murcia, los municipios comprendidos en su territorio constituyen elemento básico vertebrador del territorio regional, al que viene vinculada su población ${ }^{7}$.

La Ley regional 6/1988, de 25 de agosto, no contiene sin embargo una regulación de las competencias municipales en materias de la competencia autonómica; no obstante lo cual reconoce esta Ley una serie de principios —entre ellos el de autonomía y el de descentralización-, y de técnicas de gestión in situ de competencias, cuya finalidad no es otra que la de lograr la mayor proximidad de la gestión administrativa a la población y asegurar el establecimiento y adecuada prestación de los servicios municipales ${ }^{8}$. Objetivo que ya en los albores de la autonomía regional murciana había propiciado la Ley 7/1983, de 7 de octubre, de descentralización territorial y colaboración con las entidades locales.

Asimismo, y en consonancia con el EARM, cuyo artículo 3 incluye a las comarcas en su organización territorial, la Ley autonómica 6/1988 prevé la posibilidad de su creación: no las establece ni regula, sino que remite a su disposición por Ley de la Asamblea regional, limitándose a establecer la forma como ha de promoverse la iniciativa y el procedimiento a seguir como presupuesto, en el ámbito administrativo, de modo previo a la actuación en sede parlamentaria ${ }^{9}$. Ni que decir tiene que las comarcas podrían configurarse como entidad local (artículo 3.2, párrafo 2, del Estatuto de Autonomía), en cuyo supuesto la comarcalización regional permitiría operar una auténtica descentralización, intermedia, entre la Administración autonómica y la municipal; si bien no cabe descartar una

\footnotetext{
${ }^{7}$ Arts. 3.1 y 6.1 del Estatuto.

${ }^{8}$ Artículos 3 y 4 de la Ley autonómica 6/1888 citada.

${ }^{9}$ Artículos 59 a 61 de la Ley autonómica 6/1988, de Régimen Local.
} 
solución meramente desconcentradora, de configurarse la comarca como una división territorial interna de la Administración de la Comunidad Autónoma, para el ejercicio de competencias propias de ésta (hipótesis que, por ende, quedaría fuera de los presupuestos y ámbito propios del Pacto local). Que ni una ni otra fórmula hayan cristalizado hasta el momento en el ordenamiento autonómico, no supone descartar su posibilidad, en uno u otro sentido, como es lógico, dadas las previsiones estatutarias y legales indicadas, aunque forzoso es reconocer hoy por hoy las dificultades de incorporar este tipo de organización, que supondría una reforma general de la planta de la Administración local en la Región de Murcia, con este nuevo escalón administrativo, intermedio, cuyo establecimiento exigiría, además, de precisas actuaciones administrativas y legislativas, al proceso del pacto local abierto y en trance de negociación ${ }^{10}$.

Tampoco cabe desconocer, en fin, la referencia que el EARM hace a otros tipos de entes locales: las mancomunidades intermunicipales, las áreas metropolitanas y las entidades de ámbito territorial inferior al municipal $^{11}$. En especial, parece indudable que la clásica fórmula de asociacionismo intermunicipal que constituyen las mancomunidades, permite dar respuesta adecuada y concreta a situaciones deficitarias en la prestación de servicios públicos locales, aunque no pueda generalizarse de modo abstracto ${ }^{12}$. La voluntariedad de su creación, que las caracteriza, no es un elemento desdeñable en su aplicación, que ya cuenta por lo demás con interesantes experiencias en la Región.

\footnotetext{
${ }^{10}$ La configuración legal de la comarca en la Ley 7/1985 (art. 42), según la interpretación dada por la s. TC 214/1989, de 21 de diciembre, limita mucho sus posibilidades como entidad local. Tampoco tendría mucho sentido, parece, como organización autonómica periférica, alternativa de la municipal, que responde mejor a la descentralización que el Pacto Local pretende. Como ha considerado A. Garrorena Morales, hay que cuidar que las comarcas no nazcan enfrentadas con los municipios que las integren, ver cómo se conjuga esta creación de entidades comarcales —a las que habrá que trasladar competencias municipales - con el también deseado fortalecimiento competencial de los municipios al que referíamos hace un instante, y sobre todo ser consciente de eso que algún autor ha llamado el «mayor valor» de la comarca para las Comunidades uniprovinciales, esto es, de que, en ellas, ausente la provincia, ninguna entidad de naturaleza local —como no sea la comarca - está llamada a realizar la mediación entre los municipios y la Comunidad Autónoma (La autonomía murciana, un intento de identificación, Consejo Jurídico de la Región de Murcia. Murcia, 2000, p. 85).

${ }^{11}$ Artículos 3.3 y 4, EARM.

${ }^{12}$ Remito a las consideraciones que he hecho a este respecto en «La aprobación definitiva de la constitución y estatutos de mancomunidades intermunicipales», Rev. de Estudios de Administración Local y Autonómica, n. 251 (1991), p. 465 y sgs. En concreto, en la Región de Murcia, se han constituido varias mancomunidades, para la gestión de servicios urbanos (en la Vega Media del Segura), servicios sociales (de la Comarca Oriental, del Valle del Ricote, del Sureste, del Río Mula, del Noreste, del Mar Menor; y de Águilas y Puerto Lumbreras), y de servicios turísticos (del Mar Menor).
} 


\section{FUNDAMENTOS DEL PACTO LOCAL AUTONÓMICO: DESCENTRALIZACIÓN, AUTONOMÍA, SUBSIDIARIEDAD Y EFICACIA ADMINISTRATIVA. EL PRINCIPIO DE IGUALDAD}

1. El calificativo de segunda descentralización, también utilizado para referirse usualmente al Pacto local, en la relación Comunidad AutónomaEntidades Locales, resulta bien expresivo del objeto que se pretende: efectuar la traslación de determinados ámbitos competenciales de aquélla a los municipios. Revitalizar la vida local a través de un proceso de descentralización territorial constituye el objetivo, aun cuando la gestión de algunas competencias de titularidad autonómica pueda considerarse suficiente para ello mediante la aplicación de técnicas de carácter meramente organizativo — sin cesión de su titularidad—, de asociacionismo de carácter inter-administrativo, o la institución cuando proceda de ciertos tipos de entes no territoriales, en caso de que la realización de ciertos intereses locales así lo exija o lo haga conveniente.

Cuando se utiliza el vocablo descentralización para referirse e incluir en ella estos otros supuestos, es evidente que no se hace digamos en sentido técnico-jurídico, tal y como suele utilizarse en la dogmática administrativa, con referencia ésta a un mecanismo de transferencia de ámbitos competenciales, que la descentralización como técnica jurídica conceptualmente supone. Ahora bien, cuando de la descentralización se habla como principio, no se define, ab initio al menos, como concepto técnico-jurídico, sino más bien como una tendencia de política administrativa, vinculada no sólo al régimen constitucional sino también a las necesidades prácticas de la vida política y administrativa, que abarca una amplia gama de modalidades y grados: una variedad de posibilidades que no sólo incluye el sentido estricto del término, sino que asimismo engloba supuestos que no constituyen transferencia de competencias propias: en virtud del principio de descentralización también se delegan atribuciones de una Administración pública de base territorial a otra de ámbito inferior ${ }^{13}$. El deslinde por ello del supuesto de las «transferencias» que supone el concepto técnico de descentralización administrativa de competencias, no agota el contenido del principio, que incluye también otros tipos de cesiones de menor alcance funcional, que la realidad política y el consenso básico que

\footnotetext{
13 J. Rivero: Droit Administratif, Edit. Dalloz, París, 1980 (p. 305 y s.). Asimismo, A. NiETo: «La organización local: uniformismo y variedad», en Descentralización administrativa y organización política (dir. S. MarTín-Retortillo), Edit. Alfaguara, Madrid, 1973, tomo II (p. 21 y s.). E. GaRCíA DE ENTERRÍA: Estudios sobre autonomías territoriales, Madrid, 1985. A. IGLESIAS MARTín, $o b$. cit. en nota 3 (p. 149 y s.).
} 
el Pacto local establezca pudiera hacer aconsejables e incluso convenientes en otros supuestos de traslación de funciones de la Comunidad Autónoma a los municipios. Es, pues, evidente que es este sentido principial del vocablo descentralización, el que se emplea en el uso que del mismo se hace para calificar el pacto local como «segunda descentralización», no en su sentido técnico-jurídico de la dogmática iusadministrativista.

El deslinde de fórmulas de cesión de funciones administrativas al objeto de nuestro tema, dentro de la gama de posibilidades que el principio de descentralización ofrece, no es, sin embargo, óbice a que, del conjunto de técnicas jurídicas utilizables, se utilicen unas y otras, según el contenido y extensión que quiera o proceda dársele a la traslación, ya que todas ellas responden a la necesidad de acercar la decisión y la gestión de los asuntos que más directamente conciernen a los ciudadanos a las entidades administrativas más próximas a éstos, por ende a la comunidad social a cuyos intereses esos asuntos se refieren. Elemental constatación ésta que ya hiciera en nuestra doctrina Martín Mateo ${ }^{14}$, al decir que si la Administración quiere marchar al ritmo de los tiempos, forzosamente habrá de agilizar sus operaciones confiando responsabilidades a otros centros secundarios de poder que obren con inmediación a los problemas y con una cierta independencia, en cuyo ámbito — dice— surge insensiblemente la Administración local.

Las ventajas de la descentralización territorial han sido señaladas desde la doctrina clásica, que ha resaltado su significación política derivada del principio democrático presente en las comunidades locales, más allá de su consideración como técnica de administración, de modo que las razones de la descentralización no son sólo de orden administrativo sino de orden constitucional ${ }^{15}$. La verdadera descentralización siempre ha sido considerada como corolario necesario de un orden democrático y se realiza mejor en el nivel del gobierno local, especialmente donde existen formas de descentralización de tipo autonomista. De aquí que venga justificado y sea necesario para que las Comunidades Autónomas avancen en un proceso de descentralización intra-comunitaria ${ }^{16}$. El Tribunal Constitucional, en su sentencia 11/1999, de 11 de febrero, ha señalado que «la clave de las relaciones Comunidad Autónoma versus Ayuntamiento radica en que a aquélla, con un ámbito territorial más extenso y una dimensión política distinta, no

\footnotetext{
${ }^{14}$ El horizonte de la descentralización, IEAL, Madrid, 1969, p. 33.

${ }^{15}$ M. Hauriou: Précis de Droit administratif et de Droit Public, París, 1983, p. 86.

16 J. M. Boquera Oliver: «Comunidades Autónomas y Administraciones Locales», Rev. de Estudios de la Vida Local, n. 219 (1983), p. 409.
} 
le es lícito sin embargo exceder los límites que le son inherentes, ya que toda extralimitación iría en detrimento de la Administración municipal, dotada también de autonomía, si bien de distinto cariz, con infracción del reparto territorial de los poderes públicos configurado por la Constitución».

Es indudable que, con ello, en una Administración pública descentralizada, no sólo se facilita la gestión in situ de los asuntos públicos, en el ámbito social correspondiente; también se canaliza de modo eficaz la participación de la propia comunidad en la atención y resolución de sus intereses comunes propios, lo que conecta con el principio de autonomía municipal.

2. Configura la vigente Constitución un modelo de Administración y de régimen local que, en contraposición al precedente, viene a fundamentarse también en el principio de autonomía local: reconoce y garantiza aquélla, dentro de la organización territorial del Estado-comunidad, que el municipio ha de tener a su cargo la gestión autónoma de los intereses propios de la comunidad social vecinal, cuyos intereses ha de gobernar y administrar por ello ${ }^{17}$. Así resulta del artículo 137 del texto fundamental, que refuerza, en íntima vinculación con el principio de democracia local, el artículo 140 del mismo, al atribuir a sus órganos representativos el «gobierno y administración» de estos intereses generales en el ámbito administrativo local. De donde la configuración que, según este modelo institucional, hace la LBRL del municipio como entidad local básica y que en su estructura orgánica constituye cauce inmediato de participación en los asuntos públicos de los ciudadanos, que institucionaliza de forma autónoma y gestiona los intereses propios de la colectividad vecinal $^{18}$.

Supone esto que los municipios, así configurados en nuestro ordenamiento desde sus bases constitucionales, tienen un poder y capacidad para

\footnotetext{
${ }^{17}$ Con carácter general puede verse, L. Parejo Alfonso: Garantía institucional y autonomía local, IEAL, 1983; A. Embid Irujo, «Autonomía municipal y Constitución: aproximación al concepto y significado de la declaración constitucional de autonomía municipal», REDA, núm. 30, pp. 437 y ss.; A. Fanlo Loras: Fundamentos Constitucionales de la Autonomía Local, Centro de Estudios Constitucionales, Madrid, 1990; GARCía MACHO: «La autonomía municipal y su protección en la Ley de Bases de Régimen Local», RAP, núm. 109, 1986, pp. 413 y ss.; J. Leguina Villa, «Gobierno Municipal y Estado Autonómico», RAP, núms. 100-102, vol. III, 1983, pp. 2187 y ss.; R. MARTín MATEO: «La autonomía local y el sistema normativo español», RAP, núm. 94, 1981, pp. 53 y ss.; y F. Sosa WAGNER, «La Autonomía Local», en Estudios sobre la Constitución española, en obra homenaje al prof. GARCíA DE ENTERRÍA, tomo IV, pp. 3207 y ss.
}

${ }^{18}$ Artículos 1.1 y 11.1 de la Ley 7/1985, de 2 de abril, de Régimen local. 
decidir, por sí mismos, si bien que en el marco de la ley, todos aquellos asuntos que a la comunidad local directamente le conciernen como asuntos propios de ella. No sólo implica así la autonomía local una facultad o poder de autonormación - la llamada potestad de ordenanza, reglamentaria-, también incluye capacidad de autogobierno para poder elegir y decidir, entre varias opciones posibles, y de forma libre y autorresponsable, aquella opción que, para realizar determinados intereses de la comunidad local, estime oportuno y conveniente. Parece indudable que, aunque inicialmente se considerase por el Tribunal Constitucional que, a diferencia de la autonomía propia de las Comunidades Autónomas — política y no sólo administrativa - , la de las entidades locales es de naturaleza administrativa ${ }^{19}$, asimismo incluye ésta un componente político indudable ${ }^{20}$.

Ni que decir tiene que la autonomía municipal, en su doble dimensión - sustantiva, relativa a un ámbito de intereses propios locales, y jurídica e instrumental, que exige asimismo de un ámbito de competencias y potestades que permita realizar esos intereses—, viene limitada jurídicamente: presupone y no puede oponerse al principio de unidad política y jurídica básica, dentro de la cual, como ha señalado la jurisprudencia constitucional, alcanza su verdadero sentido. Al no delimitar, sin embargo, la Constitución el contenido de la autonomía municipal, y ser por ello la Ley la encargada de determinar cuáles son esos intereses locales y la que, por ende, atribuya a los municipios las competencias que sean necesarias para atenderlos y satisfacerlos, han de ser, pues, el legislador estatal y el de las Comunidades Autónomas quienes al regular las distintas materias, según sus respectivas competencias, han de delimitar y definir un ámbito competencial propio de los municipios, aunque el alcance de las competencias locales pueda ser y sea diverso - como competencias exclusivas unas veces o compartidas en otras- según que se refieran materialmente a inte-

\footnotetext{
${ }^{19}$ La citada sentencia del TC de 28 de julio de 1981, FJ 3. ${ }^{\circ}$, dice que «la Constitución prefigura una distribución vertical del poder entre entidades de distinto nivel que son fundamentalmente el Estado, titular de la soberanía, las Comunidades Autónomas, caracterizadas por su autonomía política, y las provincias y municipios, dotados de autonomía administrativa de distinto ámbito».

${ }^{20}$ Considera en este sentido en la doctrina el profesor PAREJo Alfonso, que la diferencia entre las distintas autonomías territoriales reside no en la naturaleza sino en el alcance de cada una de ellas: todas las autonomías territoriales — dice- tienen sustancia política, ocurriendo sólo que las posibilidades de opción son más amplias en el caso de las Comunidades Autónomas, en cuanto pueden formalizar su voluntad en actos con valor y eficacia de ley, que la potestad normativa local sólo mediante ordenanzas y reglamentos se ejerce y manifiesta (Rev. Andaluza de Administración Pública, n. ${ }^{\circ}$ 42, 2001, p. 52). Asimismo, en «La autonomía local», en Rev. de Estudios de Administración Local y Autonómica, n. 229 (1986). En el mismo sentido, M. SÁnCHEZ MoRón dice que la autonomía local no es meramente administrativa sino vehículo y forma de participación política, instancia de distribución vertical del poder (La autonomía local, Civitas, 1990); y J. LEGUINA VILLA, cit. en la misma nota (p. 2189).
} 
reses locales peculiares o a intereses comunes en que concurran con otras Administraciones territoriales.

Ahora bien, aun cuando el legislador autonómico es el principal definidor de competencias locales, puesto que la mayoría de las materias asumidas por las Comunidades Autónomas — con base en el artículo 148 de la Constitución- asimismo conciernen a intereses locales, no tienen sin embargo aquéllas plena libertad para determinar el contenido competencial de la autonomía local: no sólo porque viene enmarcada y limitada la tarea del legislador por los valores y principios proclamados en el texto fundamental; también porque incluye éste la llamada «garantía institucional» -implícita en su artículo 137-, cuya garantía también opera como límite de los poderes públicos —incluso del legislador-, al tener que asegurar un contenido o núcleo esencial de autonomía local, constituida por las competencias que sean las necesarias o indispensables, a modo de mínimo por lo tanto, para que los municipios puedan cumplir su finalidad - institucional - de gestionar los intereses propios de la comunidad vecinal. A este límite mínimo, que ha de definir la competencia municipal y que asegura la garantía institucional de la autonomía local, se une por el otro lado, como límite máximo, en el que no puede entrar por ende la competencia municipal, el que viene dado sustantivamente por los intereses que son propios de la Comunidad Autónoma (intereses supralocales). Ha de consignarse, sin embargo, la consideración hecha por T. FONT Llovet, sobre la garantía institucional de la autonomía local, que ha experimentado un giro de concepción en su propio sentido y significado al socaire de la jurisprudencia constitucional ${ }^{21}$, afirmando dicho autor que dicha garantía ha pasado de considerarse en su vertiente negativa de protección frente a invasiones del Estado y las Comunidades Autónomas, a ponderarse en su dimensión positiva, esto es, de aumentar su contenido, incrementando las competencias municipales, para conseguir la mayor realización y efectividad del principio.

Estas ideas han de situarse además hoy en el contexto europeo, plasmado en la llamada Carta Europea de la Autonomía local ${ }^{22}$, que define este tipo de autonomía territorial como «el derecho y la capacidad efecti-

21 «Aproximación a la estructura de la Administración Local en España», en el Informe sobre el Gobierno Local, Madrid, 1992.

${ }^{22}$ De 15 de octubre de 1985, ratificada por España mediante Instrumento de 20 de enero de 1988 (BOE de 24 de febrero de 1989). Ha de señalarse que la Carta Europea, en cuanto incorporada al Derecho interno, como texto normativo, está siendo aplicada por los Tribunales de Justicia españoles (así, entre otras ss. del Tribunal Supremo, las de 22 de enero de 1992, 27 de mayo de 1992, 23 de abril de 1993 y 24 de febrero de 1994). 
va de las entidades locales de ordenar y gestionar una parte importante de los asuntos públicos, en el marco de la ley, bajo su propia responsabilidad y en beneficio de sus habitantes»; añadiendo otra exigencia fundamental, la de que este derecho de autonomía se ejerza por organizaciones democráticas, representativas o de participación directa de los ciudadanos. De aquí que, en el documento relativo a las bases del Pacto local - 24 de septiembre de 1996-, la Federación Española de Municipios y Provincias considerase necesario «avanzar en la autonomía local en el sentido marcado por la Carta Local europea».

No parece necesario, por lo demás, referirse aquí a los mecanismos de reacción jurisdiccional, para la protección de la autonomía local. Sí anotar, en cambio, respecto a los controles de tutela administrativa, estatal o autonómica, la exigencia de que los controles de legalidad hasta ahora incluidos en este tipo de fiscalización — administrativa-, debieran instrumentarse conforme a la normativa básica del régimen local, que supone la atribución a la jurisdicción de los tribunales correspondientes la función de control de legalidad de la actuación de los entes locales cuando éstos actúan en régimen de competencias propias ${ }^{23}$.

3. El principio de subsidiariedad supone inicialmente una delimitación de funciones y relaciones entre el ámbito de lo privado y de lo público: lo que en la sociedad y en el Estado - lato sensu - puede ser realizado de manera adecuada por los responsables del nivel o escalón más próximo a los ciudadanos, se considera que no debe atribuirse a otro más alejado, a no ser que la acción del primero no sea suficiente para lograr las finalidades pretendidas y la intervención pública aporte un plus de eficacia ${ }^{24}$.

De modo concreto, en el ámbito de lo público, el principio supone un reparto de ámbitos de funciones y poderes, entre las distintas instancias de poder, de modo que el reparto de competencias entre ellas se efectúe a partir de las más próximas a los ciudadanos; por lo tanto, a favor de la comunidad o entidad inferior, y a las instancias superiores aquellas funciones que sobrepasen la capacidad de aquélla o que exijan medidas uniformes para toda la comunidad y superior ámbito. La distribución de funciones entre los distintos niveles de organización públicos, ha de hacerse así pues atendiendo al ámbito de los asuntos o intereses y de la capacidad

\footnotetext{
${ }^{23}$ Artículos 65 y 66 de la Ley 7/1985. Sobre las «relaciones interadministrativas de supervisión y control», vid. A. JimÉnez Blanco, en Tratado de Derecho Municipal (dir. S. Muñoz Machado), Civitas, 2. a edición 2003, 1988, p. 427 y sgs.

${ }^{24}$ A. Chicharro Lázaro: El principio de subsidiariedad en la Unión Europea, Edit. Aranzadi, 2001, p. 33.
} 
de actuar de cada uno de aquéllos, comenzando por el más próximo a los ciudadanos.

Ahora bien, como criterio de organización de lo público, la subsidiariedad significa así no sólo, en su más simplista significado, supletoriedad; también significa complementariedad dentro del conjunto de la organización de las distintas partes o elementos componentes del sistema, de modo que la efectividad de los derechos de los ciudadanos, o vecinos de un municipio, venga prima facie asignada o encomendada a la organización —o Administración — pública más cercana a aquéllos en función del tipo de intereses a ordenar y gestionar según los respectivos ámbitos materiales y jurídicos.

A este respecto, se ha referido el profesor PAREJo Alfonso a la exigencia de dar la mayor efectividad a los principios de descentralización territorial y de participación ciudadana en el ámbito de lo público, que requiere - dice- la adjudicación preferente de las competencias administrativas a la instancia territorial construida constitucionalmente sobre el principio democrático (artículos 140 y 141 de la Constitución) y que, al ser Administración los entes locales, constituyen el arquetipo constitucional de autoadministración (bien directa, bien representativa), es decir, de administración participada (en el sentido fuerte o político de la expresión). En todo caso, cabe inducir un principio constitucional de preferencia de este tipo de administración - local - sobre cualquier otro y, en particular, el institucional-burocrático ${ }^{25}$.

El contexto europeo también fundamenta en virtud del principio a que nos referimos, la necesidad de potenciar a la Administración local. En el ámbito del Consejo de Europa, la Carta de la Autonomía local recoge este principio (en su artículo 4), al establecer no sólo una cláusula general de competencia de los entes locales, sino determinar asimismo, de modo más preciso que, «el ejercicio de las competencias públicas debe, de modo general, incumbir preferentemente a las autoridades más cercanas a los ciudadanos ${ }^{26}$. Lo que permite articular una Administración, a la vez, efi-

25 «Estado autonómico y Régimen Local», Rev. Andaluza de Administración Pública, n. ${ }^{\circ} 42$ (2001) p. 51. En el mismo sentido, J. L. RIVERo IsERN: «La cooperación interadministrativa local», en el n. ${ }^{\circ} 46$ (2002) de la misma Revista (p. 77 y sgs.). Asimismo, J. RodríGuEZ-Arana, estudio cit. en la nota 3 , p. 99.

${ }^{26}$ Artículo 4.3. Lo que, además, refuerza el Tratado de la Unión Europea de 7 de febrero de 1992. En su Preámbulo se dice que los Estados miembros están «resueltos a continuar el proceso de creación de una Unión cada vez más estrecha entre los pueblos de Europa, en la que las decisiones se tomen de forma más próxima a los ciudadanos, de acuerdo con el principio de subsidiariedad». Como ejemplo de lo así declarado, en el art. A de las Disposiciones Comunes del Tratado se 
caz y próxima al ciudadano, como ha considerado nuestro Tribunal Supremo en su sentencia de 20 de febrero de 1998 (Aranzadi 1603), con fundamento en el citado precepto de la Carta Europea de la Autonomía Local y de la normativa básica de régimen local (artículos 2.1 y 10.1 de la LBRL). Además, aunque la Constitución española no recoge de forma explícita el principio de subsidiariedad, esto no quiere decir que este principio sea ajeno a los valores constitucionales, ya que puede derivarse de la significación que tienen el principio de autonomía y el de descentralización, extrayéndolo del significado y potencialidad que estos principios tienen, y que permiten deducir también de ellos el de subsidiariedad como un principio organizativo de los poderes territoriales del Estado ${ }^{27}$. Cabe entender así, como ha considerado Parejo Alfonso, que el principio de descentralización del artículo 103.1 de nuestra Constitución, es el correlato constitucional del principio de subsidiariedad en la Carta Europea de Autonomía Local $^{28}$.

4. El principio de eficacia administrativa que, antes que en sentido economicista, en el terreno de la acción pública alude a la relación mediosresultados (eficiencia), y al grado de satisfacción de las necesidades colectivas a cargo de la Administración pública (en la relación de objetivos o fines -incluidos en su competencia— con los resultados), también permite fundamentar, como un mejor servicio a los ciudadanos, la acción pública local.

La exigencia constitucional de eficacia de la Administración pública (artículo 103.1 de la Constitución) también aparece recogida en los Estatutos de Autonomías, y entre ellos en el de la Región de Murcia (artículo 51.2), como un mandato, que además respecto de los municipios, viene

repite tal pretensión, mientras que en el art. B se establece que los objetivos de la Unión se alcanzarán «en el respeto del principio de subsidiariedad tal y como se define en el art. 3.B», por el que en el ámbito de las competencias compartidas y concurrentes, la Comunidad intervendrá, conforme al mencionado principio, «sólo en la medida en que los objetivos de la acción pretendida no puedan ser alcanzados de manera suficiente por los Estados miembros y, por consiguiente, puedan alcanzarse mejor, debido a la dimensión o a los efectos de la acción contemplada a nivel comunitario».

${ }^{27}$ En este sentido, J. M. BANDRÉs, en El principio de subsidiariedad y la Administración Local, Edit. Marcial Pons, 1999, p. 26 y ss., para quien el principio de autonomía y el valor de la subsidiariedad constituyen las dos ideas-fuerza necesarias y complementarias para comprender el principio de separación vertical de los poderes y el valor de la democracia en la Constitución española.

${ }^{28}$ L. Parejo Alfonso, en La potestad normativa local, Edit. Marcial Pons, 1998, pp. 15 y 16, donde considera que será en la fase infralegal del ciclo de gestión pública o de política-administración donde debe buscarse la peculiar función constitucional de la autonomía local, en tanto que lugar y forma de gobierno y administración idóneos para la mejor realización de las exigencias simultáneas del Estado democrático y social-administrativo de Derecho. 
establecido en la normativa de régimen local (artículo 6.1 LBRL), en cuanto establece el deber de prestar de forma «adecuada» los servicios a su cargo, de manera correlativa al derecho de los vecinos a obtener las prestaciones correspondientes. La legislación autonómica murciana exige, así, en caso de transferencias de competencias propias de la Comunidad Autónoma a los municipios y demás entidades locales, que no se disminuya sino que al menos se mantenga el nivel de eficacia en la prestación de los servicios ${ }^{29}$, en línea por lo demás con la exigencia de mejora de eficacia en la gestión de servicios que, como en caso de delegación, asimismo establece la normativa básica de régimen local (art. 27.1 LBRL).

Es así que el proceso descentralizador que el régimen de autonomías territoriales comporta impone no sólo evitar duplicidades innecesarias en la gestión; también exige conseguir una mejora en la calidad de los servicios que a los ciudadanos presta la Administración, sea ésta la autonómica o ya lo sea la local o municipal por cesión o transferencia de aquella. En ello se funda, igualmente, el objetivo de la Administración «única», o común, de modo que lo mismo que el protagonismo administrativo en el ámbito territorial de la Región sea conveniente que lo tenga, respecto de las funciones administrativas del Estado y, por transferencia de éste, la Administración autonómica, respecto a ésta y de modo semejante se señale la conveniencia de que igual papel lo puedan desempeñar los entes locales y básicamente los municipios: que sean éstos quienes asuman en el territorio municipal, de este modo, el carácter de Administración común, respecto a todas aquellas funciones administrativas que atiendan, bien de forma directa o bien descentralizada en lo local, a la realización de intereses y necesidades de las respectivas colectividades locales.

La doctrina ha constatado, sin embargo, el olvido de los entes locales en la realización del modelo de Administración única. Al examinar el contenido de la propuesta de ésta — se ha dicho ${ }^{30}$ — hemos podido comprobar cómo se ha dejado habitualmente de lado toda la problemática relativa a la proyección intracomunitaria de la cuestión; es decir, la propuesta centraba su atención principalmente en el plano de las relaciones entre el nivel estatal y los niveles autonómicos, relegando a las Corporaciones locales a un plano marginal. Esa marginación se pretendía — se añadepaliar formalmente con alguna referencia incidental en los diferentes documentos a la necesidad de que las Administraciones autonómicas tam-

\footnotetext{
${ }^{29}$ Artículo 9.1, c) de la Ley 7/1983, de 7 de octubre, de descentralización territorial y colaboración entre la Comunidad Autónoma y las Entidades Locales.

${ }^{30}$ R. JimÉNEZ AsEnsio: La «Administración Única» en el Estado autonómico, Edit. Marcial Pons, Madrid, 1997, p. 97.
} 
bién descentralizaran sus servicios a favor de las entidades locales. La doctrina ha criticado una y otra vez ese abandono al que se ha sometido al escalón local en el desarrollo hipotético de la idea de Administración única.

No obstante, destacados responsables del Ministerio de Administraciones públicas han reconocido la importancia de atribuir competencias a los municipios, asociando este proceso a los efectos de la llamada Administración única: «El modelo de la Administración única no se completaría — ha dicho RODRÍGUEZ-ARANA ${ }^{31}$ - si no se produjese un paralelo proceso de desconcentración de competencias de la Administración autonómica hacia los Ayuntamientos y Diputaciones en todos aquellos servicios en que su prestación por estos entes redunda en un mejor servicio al ciudadano».

La consecución del pleno desarrollo del gobierno local y la definitiva implantación de la Administración común exige, pues, en definitiva, la puesta en marcha por cada Comunidad Autónoma, de procesos de transferencias o delegaciones de competencias en los entes locales ${ }^{32}$, lo que permitiría no sólo reforzar el papel de éstos en cuanto Administraciones más próximas a los ciudadanos, sino también prestar a éstos unos servicios de manera más cómoda y eficiente, en términos de eficiencia no ya económica y administrativa, también en definitiva social.

5. El principio de igualdad jurídica, recogido en el artículo 14 de la Constitución, es bien sabido que no puede ser interpretado como un mandato de uniformidad del Derecho aplicable en todo el territorio español que excluya o se oponga a la diversidad jurídica derivada del ejercicio de las competencias propias de las distintas Comunidades Autónomas y, en consecuencia, de la pluralidad de ordenamientos existente. Sí se exige, sin embargo, una situación de igualdad entre los ciudadanos respecto de las Administraciones públicas, en cualquier parte del territorio español en que aquéllos se hallen, en cuanto a la uniformidad de las condiciones y normas básicas a que las distintas Administraciones públicas, incluidas las autonómicas y locales, vienen sujetas.

Pues bien, conforme a estas exigencias constitucionales y a las de unidad y solidaridad territorial que en la propia Constitución se establece ${ }^{33}$, en conexión con la de «asegurar a todos una digna calidad de vida», cuya

\footnotetext{
31 «Administración Única y Pacto Local», Revista de Estudios de la Administración Local y Autonómica, núms. 271-272 (1996).

32 J. RodRÍGUEZ-ARANA: «El fortalecimiento del poder local», cit. en nota 3, p. $100 \mathrm{y}$ sgs.

${ }^{33}$ Artículos 138 y 139.1 de la Constitución.
} 
exigencia se fundamenta en otros preceptos del texto constitucional ${ }^{34}$, se ha deducido del mismo un principio de uniformidad de las condiciones de vida en todo el territorio nacional, que limitaría al principio de autonomía territorial $^{35}$, y de cuyo principio de uniformidad de condiciones la igualdad viene a constituir uno de sus elementos componentes. No significa esto, sin embargo, que las situaciones jurídicas de los ciudadanos hayan de ser las mismas en todas las partes del territorio español, sino tan sólo la prohibición de que por razón de vecindad administrativa pueda discriminarse entre los ciudadanos de unas y otras Comunidades Autónomas ${ }^{36}$. Limitación que, en último término, cabría hacer extensiva asimismo, dentro del territorio de una Comunidad Autónoma, a los vecinos de unos y de otros municipios.

¿Significa esto que todos los municipios situados en el ámbito de un determinado territorio autonómico tienen el mismo derecho a recibir en las mismas condiciones de equivalencia y nivelación competencial, todas las transferencias y cesiones de competencias que, a través del Pacto local, pudieran determinarse? La respuesta que al menos inicialmente pudiera darse en sentido positivo a esta cuestión, cabe pensar que tendría que tener en cuenta inevitablemente la realidad fáctica de los distintos municipios y que todos éstos, con especial referencia a los pequeños y medianos, no reúnan en su caso las condiciones de capacidad necesaria para organizar y gestionar por sí mismos complejas y costosas obras y servicios públicos. Cabalmente por ello el legislador ha tenido en cuenta la diversidad municipal, empezando por la normativa básica del régimen local, que condiciona como es sabido la prestación de determinados servicios municipales a la distinta entidad poblacional de determinados grupos de municipios (artículo 26 de la Ley 7/1985), y que incluye, como condición jurídica de atribución a éstos de competencias estatales y autonómicas, la capacidad de gestión que tienen (artículo 2 de esta Ley) ${ }^{37}$.

\footnotetext{
${ }^{34}$ Artículos 9.2; 40.1; y 130.

${ }^{35}$ Explícita referencia a este principio se hace en las sentencias del TC 71/1982, de 30 de noviembre, y 15/1989, de 26 de enero. En la doctrina, J. M. ${ }^{a}$ B BAÑo LEón: Las autonomías territoriales y el principio de uniformidad de las condiciones de vida, INAP, 1989. Sobre la tensión de este principio y la preocupación igualitaria que implica con el de autonomía territorial, J. Pemán Gavín: «Acerca de la uniformidad de las condiciones de vida en el Estado de las Autonomías», Rev. de Administración Pública, n. 119 (1989), p. 173 y sgs.; y en Igualdad de los ciudadanos y autonomías territoriales, Edit. Civitas, 1992.

${ }^{36}$ BAÑo LEÓN, ob. cit., p. 330.

${ }^{37}$ Es básico — dice J. L. RIVERo Isern (estudio cit. en la nota 43) — que haya tratos distintos para municipios distintos (p. 91).
} 
En lógica y debida conexión con esta normativa básica estatal, en la Comunidad Autónoma de la Región de Murcia, la Ley 7/1983, de 7 de octubre, recoge a nuestro juicio la clave para resolver la cuestión planteada. Es cierto que la igualdad exige identidad de supuestos para identidad de hechos: por ende, en nuestra materia, de la realidad fáctica municipal - demográfica, técnica y económica, básicamente- respecto a la respuesta que haya de darse en términos de transferencias y cesiones de competencias; pero dado que, en el presupuesto jurídico legal, se incluye la exigencia de que de estas transferencias o, en su caso delegaciones o encomiendas de la Comunidad Autónoma a las Corporaciones municipales, «no pueda derivarse en ningún caso trato discriminatorio entre las diferentes entidades comprendidas dentro del territorio regional», según establece la citada Ley autonómica —en su artículo 5.1, inciso final-, la solución habría de venir dada, a nuestro modo de ver, por la posibilidad de que la identidad se logre, cuando no sea posible inicialmente en atención a cada municipio aisladamente considerado, acudiendo a la agrupación de varios municipios, bien en el ámbito territorial (mediante la constitución en su caso de comarcas, previstas en el Estatuto de Autonomía y en la Ley regional de régimen local) o bien institucional (por la vía de mancomunidades inter-municipales, o de la creación en su caso de consorcios), que permitiera contar por cualquiera de estas vías con espacios idóneos, adecuados para dotar a los servicios transferidos en estos supuestos, mediante agrupación de varios municipios, con medios técnicos, materiales y personales, que posibilitaren de esta forma la necesaria gestión en términos de aptitud y suficiencia.

\section{COMPETENCIAS AUTONÓMICAS EN MATERIAS DE INTERÉS LOCAL, CON ESPECIAL REFERENCIA A LA COMUNIDAD AUTÓNOMA DE LA REGIÓN DE MURCIA}

Determinar qué competencias autonómicas son susceptibles de cesión o transferencia, en mayor o menor medida, a los municipios, exige delimitar qué materias se hallan incluidas en el ámbito dispositivo de la Comunidad Autónoma. No basta con examinar la normativa básica y de régimen local, con todo y con ser ésta presupuesto imprescindible y condicionante para el legislador autonómico; es preciso hacerlo también de modo específico, respecto a cada una de aquéllas — como aquí se hace respecto a la de la Región de Murcia - para referirse a la normativa reguladora de cada sector de actividad administrativa, ya que sólo así será posible conocer de modo concreto, en el ámbito autonómico, las competencias que los municipios situados en su territorio tienen asignadas por las leyes sectoriales correspondientes. 
En el análisis de la legislación autonómica en materias en las cuales, según la normativa básica de régimen local (art. 25.2 de la LBRL), existe un interés local, habrá de determinarse y valorarse hasta qué punto el principio de autonomía local y su garantía institucional ha sido cumplido, y en todo caso qué posibilidades existen para hacerla efectiva en términos de competencias aún susceptibles de ceder mediante las fórmulas adecuadas, a los municipios; atendiendo para ello, conforme al artículo 2 de la LBRL, no sólo a las características de la actividad administrativa en los sectores de que se trate, en las respectivas materias, sino igualmente respecto a la capacidad de gestión de los entes locales, que pudiera modular en concreto, e incluso diferenciar de forma justificada en su caso el alcance de la asignación, cesión o transferencia, de determinadas funciones.

Del examen comparativo entre la legislación básica de régimen local - fundamentalmente, del citado artículo 25.2 de la LBRL - y el Estatuto de Autonomía - así, en el EARM (artículos 10 a 12)—, resulta una relación de materias en las que los municipios han de tener un determinado ámbito funcional de competencias que les permita hacer efectivos intereses de la comunidad vecinal. Esta relación de materias es la siguiente:

1. Urbanismo. El legislador autonómico, que ostenta por lo general exclusividad de la competencia en esta materia (así, el artículo 10.1, número 2, EARM), viene obligado a atribuir competencias a los municipios para la «ordenación, gestión, ejecución y disciplina urbanística» (en su artículo 25.2, d, LBRL). Incumbe al municipio algo tan consustancial a la realidad local ${ }^{38}$ como es ordenar y gestionar el mantenimiento, la rehabilitación y el desarrollo de la ciudad, de la urbs. Se trata, sin embargo, de una materia y unas funciones centralizadas en nuestro ordenamiento jurídico según las precedentes regulaciones legales estatales del suelo y de la ordenación urbana, que si bien ha sido sustituida ahora por la correspondiente legislación territorial, mantiene aún ciertos controles administrativos autonómicos, que cabría reconsiderar y, en su caso, suprimir.

Una vez afirmada la necesidad de que las Comunidades Autónomas legislen en materia de urbanismo, dada la exclusividad de su competencia estatutaria, y en los términos que en la famosa sentencia del Tribunal Constitucional 61/1997, de 20 de marzo, se han establecido, por lo que se refiere a la Región de Murcia, la Ley 1/2001, de 24 de abril, del Suelo, ha venido a sustituir a la precedente legislación estatal. En su artículo 8, determina esta Ley que las competencias en materia de urbanismo corres-

\footnotetext{
${ }^{38}$ La Sentencia del TS de 13 de noviembre de 1989 (Arz. 8184) califica como «natural» la competencia del municipio en esta materia.
} 
ponden a los Ayuntamientos, a excepción de aquellas que expresamente confiere la Ley a la Administración regional; cláusula general en virtud de la cual los municipios tienen competencia en esta materia, donde el despliegue de su autonomía les permite llevar a cabo todas aquellas actuaciones que no estén de forma explícita excluidas de la competencia local. Las excepciones a este principio, que juega así a favor de la autonomía municipal, han de venir por ello cabal y estrictamente justificadas por la existencia de un interés público supramunicipal y situarse, además, en el marco y contexto básico de relaciones interadministrativas que la LBRL regula en sus artículos 55 a $62^{39}$.

La supresión de controles administrativos autonómicos relativos a la aprobación del planeamiento urbanístico municipal se sitúa así en esta línea general que supone el reconocimiento de la autonomía local, aunque con la excepción del plan general municipal de ordenación urbana, cuya aprobación definitiva se reserva en todo caso a la Administración regional ${ }^{40}$. Aunque el ámbito y alcance de este control de tutela administrativa autonómica ha de limitarse a aspectos de legalidad y de ordenación supramunicipal, continuando la línea del precedente modelo normativo estatal, según la interpretación que del mismo se hizo por la jurisprudencia del Tribunal Supremo, a partir de su famosa sentencia de 13 de julio de 1990 (Aranzadi 6034), fijando el alcance del precepto contenido en el artículo 41.2 de que la Ley del Suelo estatal de 1976, parece que el régimen básico de controles supralocales de la actuación municipal ha de atenerse hoy al régimen —básico— de la citada Ley 7/1985, el cual no justifica ya, a nuestro modo de ver, en un sistema de control jurisdiccional ${ }^{41}$, la pervivencia de controles de aspectos de legalidad de la actuación administrativa local por vía de tutela administrativa ${ }^{42}$.

\footnotetext{
${ }^{39}$ Remitimos a lo expuesto en otro lugar: La ordenación territorial y urbanística de la Región de Murcia. Comentarios a la Ley 1/2001, de 24 de abril, del Suelo de la Región de Murcia, Edit. Diego Marín, 2002 (comentario al art. 8 y sus concordantes). Vid. asimismo mi estudio cit. en la nota 42; y J. L. De La Valuina: «Autonomía local y aprobación por delegación de los planes generales de urbanismo», en Rev. de Estudios de la Administración Local, n. ${ }^{\circ} 288$ (2002), p. 11 y sgs., y J. L. MeILÁn GIL: «Autonomía local y planeamiento urbanístico» en la misma Revista y núm., p. 39 y sgs.

${ }^{40}$ Así, los artículos 136 a 138 de la Ley regional 1/2001 cit. (Comentarios citados en la nota anterior, p. 237 y sgs.).

${ }^{41}$ Artículos 65 y 66 de esta Ley, en conexión con el 19, c) y d) de la Ley 29/1998, de 13 de julio.

${ }^{42}$ Remito a mi estudio «La autonomía municipal en el trámite de elaboración y aprobación del planeamiento urbanístico general», en Rev. Práctica Urbanística, n. 6 (2002), Edit. La Ley (p. 42 y sgs.).
} 
De otra parte, por lo que se refiere a la acción de disciplina urbanística, la reciente Ley del Suelo murciana exceptúa de la cláusula general de competencia municipal antes aludida, determinados supuestos en los cuales se confieren a la Administración regional atribuciones para autorizar determinados usos, obras e instalaciones en suelo no urbanizable (artículos 76.2 y 77.2) y en suelo urbanizable sin sectorizar (artículos 83.4 y 86), que configura como supuestos de actuación regional directa. Como también regula la actuación de la Administración regional por vía de sustitución en el ejercicio de la competencia local, en determinados supuestos, por falta de ejercicio de la competencia municipal relativa a la suspensión de obras o usos sin licencia o que incumplan las condiciones de ésta (artículo 227.2), así como la posibilidad de ordenar aquélla la incoación de expediente sancionador con pieza separada de restablecimiento de la legalidad (artículo 228.1), y el supuesto de inactividad municipal cuando proceda la revisión de oficio de licencia u orden de ejecución (artículo $232.4)^{43}$.

Estrechamente relacionada con las competencias en materia de urbanismo se halla, por otro lado, la que se refiere a la «promoción y gestión de viviendas» (artículo 25.2, d, Ley 7/1985), donde la existencia de un interés municipal justifica y determina, en razón asimismo del principio de autonomía local por ello, que el legislador básico haya establecido también un deber para el legislador sectorial, en nuestro caso el autonómico atendiendo a las exclusividad de su competencia estatutaria, que le obliga a atribuir competencias a los municipios de modo y manera que éstos puedan atender también a la gestión del interés local que supone la evidente necesidad de actuar en esta materia. En la Región de Murcia, la Ley autonómica 1/1999, de 17 de febrero, regula la actuación del organismo autónomo Instituto de Vivienda y Suelo, con importantes funciones en la materia, y en las que incluye una especial colaboración con las Corporaciones locales, mediante la posible constitución y participación con éstas en «sociedades, empresas y consorcios», así como «suscribir convenios para la promoción y gestión de viviendas de promoción pública» ${ }^{44}$; mecanis-

\footnotetext{
${ }^{43}$ Supuestos cuya regulación quizá fuera conveniente reconsiderar, por las razones que hemos expuesto en otro lugar, en atención de las consideraciones que, conforme al principio constitucional de autonomía local, ha hecho en varias sentencias el supremo intérprete de la Constitución, y entre ellas la más reciente de 11 de diciembre de 1999 —n. ${ }^{\circ} 11 / 1999-$, donde se determina que los supuestos de subrogación han de encajar en el artículo 60 de la Ley 7/1985, y que el control administrativo de legalidad ha desaparecido en el marco de esta ley, por lo cual los supuestos de subrogación habrían de canalizarse por las vías de los artículos 65 ó 66 de esta Ley básica, y que sólo por ello pueden encontrar solución en sede jurisdiccional (La ordenación territorial y urbanística ..., cit. en la nota 39, Comentarios dedicados a cada uno de los referidos artículos).
}

${ }^{44}$ Artículo 5.1, apartados a) y c) de la citada Ley $1 / 1999$. 
mos jurídicos que, en principio al menos, podrían cubrir con suficiencia la posibilidad de realizar las políticas públicas, autonómica y municipal, de forma coordinada, en una materia como ésta de la vivienda y suelo, mediante actuaciones de promoción e incluso de gestión que permitieran abaratar el precio de la vivienda, desde sus presupuestos urbanísticos, de disposición de suelo que, en el ámbito local, incluye el mecanismo de los patrimonios de suelo que la Ley 1/2001 regula, y que incluyen entre sus posibles destinos el de construcción de viviendas de protección pública.

2. Educación. Supuesto que los municipios no sólo han de participar en la programación de la enseñanza y crear centros públicos en esta materia, conforme a la legislación estatal, sino también realizar funciones en los demás aspectos a que esta normativa asimismo se refiere, en cuanto a las posibilidades de actuación municipal en la Administración educativa autonómica, y que se refieren especialmente a los problemas de financiación de la conservación, mantenimiento y vigilancia de los edificios escolares dedicados a educación en sus niveles infantil, primaria o especial. El ámbito del Pacto local en esta materia habría de situarse no tanto en el terreno de las transferencias de funciones y servicios cuanto en el de llegar a posibles compromisos con la Administración educativa autonómica de modo que ésta contribuya a financiar y cooperar, por vía de convenios, en estas atenciones hoy a cargo municipal ${ }^{45}$.

3. Sanidad. En esta materia, también existe un interés local básico que obliga también al legislador sectorial a atribuir en ella competencia a los municipios para la «protección de la salubridad pública» ${ }^{46}$, justifica y determina que la normativa estatal contenida en la Ley 14/1986, de 25 de abril, cuyo artículo 42 establece de modo general, para todo el territorio nacional, las competencias de los municipios, y posibilita que éstos hagan efectiva la existencia de centros y establecimientos de salud municipales, aunque integrados en el Servicio de Salud de la correspondiente Comunidad Autónoma.

\footnotetext{
${ }^{45}$ En concreto, la propuesta de la Federación de Municipios de la Región de Murcia para la negociación del pacto local en este ámbito, incluye que la Administración autonómica asuma las competencias - más bien cargas - residuales de los municipios en el mantenimiento, conservación y atención de los centros públicos de enseñanza primaria, sin coste alguno para aquéllos; mientras que - se propone - los municipios por su parte absorberían el personal — conserjes, limpiadoras, etc.- actualmente adscrito a estos servicios. Asimismo, la propuesta municipal incluye que la Administración autonómica incremente la financiación finalista, con cargo a los fondos de ésta destinados a educación infantil prestada por los Ayuntamientos, en ejercicio de la función colaboradora de éstos con la Administración educativa regional, mediante convenios de gestión.
}

${ }^{46}$ Artículo 25.2, h) e i) de la Ley 7/1985, básica de régimen local. 
Sin perjuicio de las competencias que de modo general, según esta normativa, ostentan los municipios, la Ley murciana 4/1994, de 26 de julio, prevé la posibilidad de delegar en los Ayuntamientos el ejercicio de otras competencias. Ahora bien, dado que el servicio de salud de la Comunidad Autónoma - el Servicio Murciano de Salud - ha recibido la oportuna transferencia de competencias del Instituto Nacional de la Salud en materia de funciones y servicios de la asistencia sanitaria pública que este organismo de la Seguridad Social gestionaba ${ }^{47}$, ello trae consigo que se trasladen ahora a la Administración autonómica las demandas que, en esta materia, la Federación Española de Municipios y Provincias había planteado al Ejecutivo estatal, respecto a la transferencia de la atención primaria de la salud y a la ampliación de las competencias mínimas municipales, que incluyan, además de las actuales de saneamiento de aguas y control de alimentos, las de potenciación de los programas de seguridad e higiene de los alimentos y del estudio de los efectos sobre la salud del medio ambiente, así como la de realizar programas de vigilancia epidemiológica.

4. Medio ambiente. La compleja normativa sectorial que regula esta materia se halla dispersa en múltiples disposiciones, reguladoras de los distintos medios y recursos naturales — suelo y subsuelo, aguas, atmósfera, etc.- - pero limitándonos aquí a la normativa autonómica de la Región murciana, la Ley autonómica 1/1995, de 8 de marzo, regula la «calificación ambiental» (en sus artículos 21 a 35) que configura como un tipo de autorización administrativa ${ }^{48}$, si bien la Ley $1 / 2002$, de 20 de marzo, con buen criterio, ha venido a configurar el acto de calificación como «informe vinculante» para el municipio en caso de implicar la denegación de la licencia o determinar la imposición de medidas correctoras; informe que se integra así ahora en el procedimiento de licencia municipal, cuyo trámite y efectos regula la Ley autonómica ${ }^{49}$. El acto administrativo autorizatorio viene a configurarse así actualmente como acto administrativo municipal, cuya adopción corresponde pues a la autoridad local —el alcalde— que por lo tanto es ahora el «órgano sustantivo», mientras que la

\footnotetext{
${ }^{47}$ El traspaso de funciones y servicios del INSALUD a la Comunidad Autónoma de la Región de Murcia se establece por el R. D. 1474/2001, de 27 de diciembre.

${ }^{48}$ El artículo 21.2 de la Ley 1/1995 configura la «calificación ambiental» como el acto final del procedimiento de autorización administrativa regulado en su artículo 28 y siguientes: se configuraba pues como una especie de acto administrativo autorizatorio.

${ }^{49}$ Artículos 28 a 32; y de modo supletorio, el Reglamento de 30 de noviembre de 1968, en materia de actividades molestas, insalubres, nocivas y peligrosas. (La Disposición adicional 6 . $^{\mathrm{a}}$ de la Ley autonómica 1/1995 establece que, en el ámbito territorial de la Región de Murcia este Reglamento estatal «no será de aplicación directa», lo que no es óbice a que lo sea de forma supletoria conforme al artículo 149.3, in fine, de la Constitución).
} 
intervención del llamado «órgano ambiental» puede producirse en el propio ámbito municipal o en el autonómico: la Ley 1/1995 atribuye, en su artículo 23, la competencia a este respecto a la propia Administración local en los municipios de más de 20.000 habitantes, pero se reserva la competencia de calificación ambiental en los municipios de población inferior, si bien admite la posible delegación a éstos en caso de que lo soliciten y acrediten disponer de los medios técnicos y personales precisos para el ejercicio de las competencias delegadas. Sin perjuicio de esto, la Comunidad Autónoma se reserva, como es lógico, la calificación ambiental respecto de actividades de ámbito supramunicipal.

Con ello, la reforma introducida por la Ley autonómica 1/2002, en la 1/1995, no sólo ha clarificado la regulación antes un tanto confusa de esta materia, con la determinación del acto de calificación ambiental como un informe del órgano ambiental (en lugar de acto resolutivo final del procedimiento administrativo - de licencia - como lo configuraba la precedente normativa legal reformada); también se reparten con ello los ámbitos de actuación que, atendiendo a los respectivos intereses concurrentes, el local y el supramunicipal, viene implícitamente a reconocer la autonomía local, al residenciar en los municipios al órgano sustantivo - resolutorio- e incluso al órgano ambiental — calificador-, bien en cuanto a éste con una competencia propia municipal o, en su caso, delegada. La ordenación legal sería, sin embargo, susceptible de mejora si, en función del interés que fundamenta la autonomía local, el supuesto de delegación relativo a los municipios de menor entidad poblacional se configurase como auténtica transferencia autonómica, en el caso de que se cumplieren los dos requisitos que la Ley 1/2002 establece, esto es, en el de que el Ayuntamiento lo solicite y acredite disponer de la necesaria capacidad de gestión, por tener los medios personales y técnicos precisos para poder ejercitar esta actuación.

5. En materia de servicios sociales, la evolución experimentada con el Estado social de Derecho ha determinado el paso de la clásica acción municipal en esta materia — sobre la beneficencia — con la implantación de todo un sistema de servicios sociales, que ha venido a englobar todo un complejo de actividades prestacionales que tienen por finalidad dar cobertura a situaciones y contingencias vitales, de personas especialmente necesitadas de determinadas atenciones por razón de sus circunstancias individuales, como es el caso sobre todo de las personas mayores, los discapacitados, los jóvenes inadaptados y las mujeres. La Ley estatal $7 / 1985$ reconoce el interés local en esta materia al establecer que los municipios han de recibir competencias del legislador sectorial para la «presta- 
ción de los servicios sociales y de promoción y reinserción social» (artículo 25.2, k), y la obligatoriedad de prestación de estos servicios en los municipios de más de 20.000 habitantes (artículo 26.1, c). La misma Ley básica, sin perjuicio de esto, admite la posibilidad de que los municipios realicen, como actividad complementaria de la propia de otras Administraciones públicas, actuaciones en materia de «promoción de la mujer».

La Comunidad Autónoma de la Región de Murcia, lo mismo que otras Comunidades Autónomas, tiene atribuida en su Estatuto de Autonomía competencia exclusiva en materia de «asistencia y bienestar social», competencia que incluye el desarrollo comunitario, política infantil y de la tercera edad, instituciones de protección y tutela de menores, promoción e integración de los discapacitados, emigrantes y demás grupos sociales necesitados de especial protección, incluida la creación de centros de protección, reinserción y rehabilitación (artículo 10.1, número 18), así como la promoción de la mujer (artículo citado, n. ${ }^{\circ} 20$ ); materias en las cuales, y en el ejercicio de la potestad legislativa autonómica, la Ley regional 8/1985, de 9 diciembre, regula los servicios sociales, que define en su artículo 3 con una gran amplitud, y establece que se constituyen un «sistema público de servicios sociales», que «procurará, con carácter gratuito y especial atención a los ciudadanos más desprotegidos socialmente, información y colaboración en relación con los recursos que, integrados en otros sistemas (pensiones, subsidios, sanidad y educación principalmente) tienen por objeto satisfacer niveles básicos de la calidad de vida y el bienestar social, estableciendo niveles de coordinación con los mismos» (artículo 1.3). Como principio básico en la materia, establece la Ley murciana, entre otros, y por lo que a nuestros efectos interesa, el principio de descentralización, «mediante el desplazamiento de competencias y gestión de los servicios hacia los órganos e instituciones más próximos al usuario, de forma que sean los Ayuntamientos y demás entes territoriales los principales gestores, asegurando una igualdad de servicios y prestaciones a todos los ciudadanos de la Región» (artículo 6.4).

Pues bien, dentro del sistema público de servicios sociales, y de modo similar a otras regulaciones autonómicas, la Ley 8/1985 distingue entre servicios sociales «comunitarios», o generales, y «especializados» ${ }^{50}$, cuya

\footnotetext{
${ }^{50}$ Se integran en los primeros el de «información y orientación» (arts. 9 y 20), «promoción y cooperación social» (arts. 11 y 12), «atención domiciliaria» (arts. 13 a 15), y el de convivencia (arts. 16 a 18); y como servicios «especializados» regula la Ley los referentes a la infancia y adolescencia (arts. 19 a 22), juventud (arts. 23 a 26), tercera edad (arts. 27 a 30), minusválidos (arts. 31 a 34), drogodependientes (arts. 35 a 42), mujer (arts. 43 a 46), minorías étnicas (arts. 47 a 50), y situaciones de emergencia (arts. 52 a 54).
} 
diferencia sirve de base de reparto de competencias y funciones, entre otros criterios, para atribuir la gestión de los primeros a la Administración regional en el supuesto de que «no sean creados por los propios Ayuntamientos en municipios con población inferior a 20.000 habitantes», y los servicios sociales especializados a los municipios dentro de su respectivo ámbito territorial, y a la Administración regional cuando excedan de este ámbito local si los municipios no creasen para gestionarlos una mancomunidad voluntaria o entidad territorial de ámbito supramunicipal (artícu$\operatorname{los} 58$ y 61$)$.

La legislación autonómica murciana atribuye así —en consonancia con la Ley básica estatal de régimen local—a los municipios de más de 20.000 habitantes tales servicios sociales como funciones propias, pero sin que ello sea óbice para que, respecto a los demás municipios, puedan éstos actuar aunque sea previa delegación de competencias efectuada por la Comunidad Autónoma (conforme prevé el artículo 65.2 de la Ley 8/1985). En cualquier caso, los órganos y unidades administrativas de gestión incluyen la posibilidad, en virtud de la potestad de autoorganización local, de instituir patronatos, consejos e institutos municipales de servicios sociales, bien como órganos desconcentrados o entes institucionales descentralizados, si bien en todo caso han de quedar integrados funcionalmente, en el sistema público de servicios sociales, bajo la planificación, programación y coordinación de la Comunidad Autónoma.

La asunción con alcance exclusivo de la competencia en materia de servicios sociales por ésta traslada por ello a la misma la cuestión de tener que ceder parte de sus competencias y ejercicio a los municipios. De hecho, sucede que la gran mayoría de los servicios indicados son gestionados por las Corporaciones locales, pero mediante fórmulas de delegación o de convenios a que se supedita el otorgamiento de subvenciones y otros tipos de ayudas autonómicas. Ante esta situación, las propuestas formuladas en 1996 por la Federación Española de Municipios y Provincias, al Ejecutivo estatal, para que sean las entidades locales quienes asuman la competencia - y la correspondiente dotación presupuestaria - relativa a la gestión y desarrollo de determinados equipamientos, servicios y programas sociales, son lógicamente extrapolables hoy a las Comunidades Autónomas.

6. En materia de consumo, el EARM atribuye, en su artículo 11.7, competencia a la Comunidad Autónoma en materia de defensa de los consumidores y usuarios, para el desarrollo legislativo y ejecución de la legislación básica del Estado; y en ejercicio de esta competencia, la Ley regional 4/1996, de 14 de junio, regula el Estatuto de los consumidores y usuarios 
de la Región. De otra parte, en el régimen local, la LBRL establece en su artículo 25.2, g, que el legislador sectorial ha de atribuir a los municipios competencias en materia de «abastos... y defensa de los consumidores», para que puedan ser atendidos asimismo en el ámbito local los intereses de éstos. La Ley autonómica 4/1996 no efectúa, sin embargo, en esta materia, una atribución de competencia a los municipios sino que se limita a hacer una referencia general, en su articulado, una y otra vez, a las Administraciones públicas con competencia para la defensa del consumidor y usuario (así, en los artículos 8,10,11,12,13, etc.), pero sin delimitar ni especificar las que corresponden a los entes locales.

Esta indeterminación de la Ley autonómica supone que las funciones que el artículo 41 de la Ley 26/1984, de 19 de julio, estatal, señala para promover y desarrollar la protección y defensa de los consumidores a llevar a cabo por las autoridades y Corporaciones locales «en el ámbito de sus competencias y de acuerdo con la legislación estatal y, en su caso, de las Comunidades Autónomas», al haberse producido la transferencia a éstas, ha trasladado al ámbito autonómico la cuestión de concretar en el Pacto local la asignación de competencias sobre consumo a los municipios. Y es así como la propuesta que en 1996 acordara formular la Federación Española de Municipios y Provincias al Estado cabe considerarla replanteada o replanteable ahora en el ámbito autonómico, sin perjuicio de su adecuación en cada caso. La propuesta incluye que la legislación —autonómica - atribuya competencias a los municipios para realizar, en principio, las funciones que determina el precepto del citado artículo 41 de la Ley estatal 26/1984, en especial de las relativas a la inspección de productos y servicios para comprobar su origen e identidad, el fomento y apoyo de las asociaciones de consumidores, y la determinación legal del alcance de la potestad sancionadora local, para que no se solape con la de la Administración autonómica ${ }^{51}$.

En lo que se refiere a este tipo de potestad administrativa, la Ley murciana 4/1986 establece en su artículo 44.2, que «en el ámbito de las Administraciones locales regirá su legislación específica» y que «reglamentariamente se establecerán, dentro de este ámbito competencial, las sanciones que corresponda imponer a cada una de las Corporaciones locales, según las bases de población y el tipo de infracciones». Ni el reenvío a la legislación de régimen local, ni el desarrollo reglamentario de la Ley autonómica previsto - pero aún no efectuado—, parecen sin embargo bas-

\footnotetext{
${ }^{51}$ Sobre esta cuestión, vid. I. SAnz Rubiales: «La competencia sancionadora en materia de consumo», en Rev. de Administración Local y Autonómica n. ${ }^{\circ} 286-287$ (2001), p. 39 y sgs.
} 
tantes para resolver la situación actual que, ante la falta de atribución de competencia sancionadora a los entes locales por la Ley autonómica ${ }^{52}$ y las dudas que suscita la aplicabilidad de la disposición adicional quinta de la Ley 31/1990, de 27 de diciembre ${ }^{53}$, parece hacer necesaria una modificación de aquélla, para evitar que las funciones de inspección que en materia de consumo realizan los municipios se limiten como se limitan simplemente hoy por hoy a tramitar los procedimientos sancionadores, pero sin poder imponer las sanciones correspondientes, elevando sus propuestas a este efecto a la Administración regional.

7. En materia de deportes, la Comunidad Autónoma de la Región de Murcia tiene competencia exclusiva en materia de «promoción del deporte» ${ }^{54}$, función que en virtud del artículo 43.3 de la Constitución se proyecta sobre el llamado deporte popular o «deporte para todos» los ciudadanos, de acuerdo con la legislación aplicable configuradora del derecho de éstos en la materia. Por su parte, respecto a las entidades locales, la LBRL fija el contenido competencial mínimo que debe ser asumido por los municipios al establecer, en su artículo 25.2, m, que éstos han de ejercer en todo caso competencia en los términos de la legislación sectorial - estatal y autonómica - en materia de actividades e instalaciones deportivas; y en el supuesto de que la población municipal exceda de 20.000 habitantes, la misma Ley impone - en su artículo 26,1, c-, al municipio, la prestación del servicio de instalaciones deportivas de uso público. Por lo tanto, el servicio deportivo municipal, que toma como base material la instalación deportiva, se configura legalmente como un servicio municipal de carácter obligatorio, cuya prestación resulta por ello exigible por los vecinos de forma correlativa, a tenor de la propia Ley básica (artículo 18.1, g).

Bajo estos presupuestos, la Ley 2/2000, de 12 de julio, reguladora del deporte en la Región de Murcia, que, como la mayoría de las autonómicas en esta materia, incluye la participación de entidades públicas en la organización administrativa correspondiente - en el Consejo Asesor Regional del Deporte, en aquélla-, determina expresamente las competencias de los municipios en materia deportiva (artículo 9), e incluye entre ellas la referente a la construcción, ampliación y mejora de las instalaciones y equipamientos deportivos municipales, su gestión y mantenimiento, así

\footnotetext{
${ }^{52}$ Dado el carácter supletorio del artículo 41 de la Ley estatal 26/1984 (s. TC 15/1989, de 26 de marzo, sobre esta Ley; y s. TS de 3 de noviembre de 1994, Arz. 8986).

${ }^{53} \mathrm{Vid}$. loc. cit. en la nota 51 , p. 41 y s.

${ }^{54}$ Artículo 10.1, n. ${ }^{\circ}$ 17, del EARM.
} 
como la cooperación en la elaboración del plan regional de infraestructuras deportivas respecto a las instalaciones a construir en el término municipal, y la ejecución de los programas de deporte escolar.

Aunque la Ley autonómica 2/2000 no incluye de modo expreso la función de planificación municipal de las instalaciones deportivas en este ámbito, es indudable que esta posibilidad viene comprendida en la potestad de planificación y no sólo de programación que los entes locales territoriales tienen básicamente en virtud de la referida normativa general de régimen local (art. 4.1, c, LBRL); sin perjuicio cabalmente, en todo caso, de las facultades de coordinación que a la Comunidad Autónoma incumbe a través del citado plan regional de infraestructuras deportivas.

Por lo que se refiere a la gestión de instalaciones deportivas, las demandas de la Federación Española de Municipios y Provincias, formuladas al Estado en 1996, incluían no sólo la gestión de las ubicadas en los centros de enseñanza - a excepción de los universitarios-, sino también de las instalaciones que son propiedad de las Comunidades Autónomas, salvo las de carácter federativo destinadas a la alta competición. Respecto a las primeras, parece que al establecer la Ley murciana 2/2000 la competencia de los municipios sobre la «ejecución de los programas de deporte escolar», sea lógico entender que esto ha de llevar como resultado a que, mediante los acuerdos o convenios a que se refiere esta Ley -en su artículo 12-, la ejecución de estos programas incluya la gestión de las instalaciones donde hayan de realizarse las actividades deportivas. De otra parte, la gestión de las instalaciones y equipamientos deportivos de la Comunidad Autónoma, cuya gestión corresponde por ello a ésta, también podría eventualmente instrumentarse para que pudieran ser gestionadas en su caso por los municipios, conforme a la Ley autonómica 3/1992, de 30 de julio, de patrimonio de la Comunidad Autónoma, mediante la técnica de la «adscripción» al municipio que lo solicite y conforme a las condiciones que se determinen (art. 27.2).

Por último, respecto a la propuesta que formulara dicha Federación para que éstos se encarguen de organizar en sus términos municipales los juegos escolares, parece que su organización y ejecución requerían de programas específicos conforme a los principios que la Ley regional 2/2000 establece —en su artículo 3. 1—, programas en cuya preparación y elaboración habría de intervenir el municipio afectado, quien asimismo y por vía de cooperación, mediante los acuerdos o convenios que resultaren necesarios, podría asumir la organización de los referidos juegos. 


\section{MODOS DE ARTICULACIÓN JURÍDICA DEL PACTO LOCAL AUTONÓMICO}

La formulación e instrumentación jurídica del pacto local autonómico supone todo un marco jurídico y conceptual, que incluye una serie de técnicas administrativas cuya aplicabilidad vendrá dada no sólo en atención de las materias y regulación actual sino también del resultado a que quiera llegarse en el proceso de negociación del pacto local

\section{Técnicas jurídicas utilizables para efectuar la cesión y ejercicio de competencias autonómicas a los municipios}

En el marco legal básico de nuestro ordenamiento, que constituyen la LRBL, y la Ley 30/1992, de 26 de noviembre, que completa en la Región de Murcia la Ley 7/1983, de 7 de octubre, hay una variada gama de técnicas jurídicas que hacen posible encauzar, modulando su alcance, la cesión de funciones y servicios de una Administración pública — la regional—a los municipios, eligiendo según las materias y supuestos la técnica adecuada, atendiendo a la naturaleza de la función a transferir y al contenido del Pacto a que se llegue eventualmente entre las partes. Las opciones o posibilidades pueden ir, a este respecto, desde reasignar una competencia administrativa como tal, que pasaría del ámbito autonómico al local, en cuyo supuesto se daría una auténtica descentralización administrativa territorial (A), o bien la cesión o traslado de la competencia autonómica en cuanto meramente a su ejercicio municipal en el supuesto de delegación de aquélla (B), con la posibilidad en fin de que la cesión se limite simplemente a actividades de tipo material en el supuesto de aplicar la técnica denominada «encomienda» o encargo de gestión (C). Supuestos que han de complementarse en su caso con fórmulas de gestión paccionada, entre las cuales destacan los convenios de cooperación interadministrativa, los consorcios y otros tipos de entes de gestión (D).

Ahora bien, dado que la posición institucional de las entidades locales en nuestro ordenamiento jurídico incluye, en virtud de su autonomía, potestad normativa — reglamentaria y de planificación-, además de poderes ejecutivos, ni que decir tiene que la descentralización territorial, no puede comportar en ningún caso, ni siquiera en el que supone una mayor intensidad en el nivel atributivo de competencias, con la transferencia de funciones propias, exclusividad plena de la competencia local. A reserva, pues, en todo caso, de la potestad legislativa autonómica, y dependiendo además de la técnica de cesión o traspaso a utilizar — según el 
alcance que a la traslación funcional se le quiera atribuir-, se producirá una situación de concurrencia de funciones, autonómicas unas y locales otras, sobre cada materia, cuyo alcance habrá de graduarse en atención al tipo de intereses generales — regionales y municipales — prevalentes y de las condiciones que se pacten para decidir el ámbito material en que haya de operar la descentralización.

\section{A) La «transferencia» de funciones autonómicas a los municipios con asignación a éstos de competencias propias}

La atribución autonómica al municipio de funciones supone definir una «transferencia» de competencia propia, cuya titularidad implica que la capacidad de decisión sobre los asuntos en la materia de que se trate va a corresponder en adelante al municipio en régimen de autogobierno y autorresponsabilidad, esto es, de manera autónoma, y sin sujeción por ello a controles de tutela administrativa de conveniencia u oportunidad de su ejercicio, sino sólo a controles de legalidad, si bien que reconducidos éstos en el ordenamiento actual, por lo general y conforme a la legislación básica estatal, al orden jurisdiccional correspondiente; aun cuando su ejercicio venga condicionado por el marco básico de relaciones de coordinación interadministrativa que la legislación estatal de régimen local establece de manera general y uniforme.

La técnica de la «transferencia» de competencia ha de articularse, pues, mediante una operación jurídica de reasignación de ésta, que supone tener que variar el ordenamiento legal, para atribuirla por norma - ley formal (art. 7.1, pfo. 2 LBRL) - en razón del principio de legalidad y jerarquía normativa. El supuesto viene a ser sustancialmente análogo al previsto en el artículo 150.2 de la Constitución, respecto del ámbito de las competencias estatales que, por vía extra-estatutaria, pueden ser objeto de transferencia por la Ley —Orgánica, en este supuesto constitucional—, pero que lógicamente, en el marco de relaciones entre las Comunidades Autónomas y las Entidades locales de su territorio, han de instrumentarse mediante Leyes ordinarias —autonómicas-, las correspondientes transferencias.

De las materias que, en principio, son susceptibles de ser objeto del pacto local autonómico, quizá sea la relativa a urbanismo la que, según el estado de su regulación actual, de forma más apropiada requiera actuar de esta manera. Así, en la Región de Murcia, si bien la Ley 1/2001, del Suelo, establece un reparto de competencias autonómicas y locales atendiendo al criterio básico del interés general respectivo, en su artículo 8 , mantiene sin embargo determinados controles administrativos de legalidad sobre dispo- 
siciones y actos municipales en esta materia que, como se ha indicado antes, más bien habría que residenciar, ratione materiae, en el ámbito local, directamente bajo control jurisdiccional. Habría quizá de reconsiderarse la regulación que la propia Ley establece en materia estrictamente urbanística, de otros controles autonómicos a que antes se ha hecho referencia (IV.1). Parece indudable que la descentralización no sólo supone y exige suprimir controles administrativos mediatizadores o sustitutivos del ejercicio independiente, sino y por esto mismo establecer un régimen que, dentro del marco de la Ley y en virtud del principio de autonomía local, posibilite la actuación municipal en una materia como la de urbanismo, tan característicamente local, en régimen de autogobierno y de autorresponsabilidad.

El recurso a la ley, en la instrumentación jurídica del pacto local, también parece necesario en materia de consumo, para habilitar en virtud de la Ley, de potestad sancionadora a los municipios, ante la indeterminación y duda razonable que suscita la regulación actual, que ha dado lugar en la práctica administrativa local, a que se limiten ésta a iniciar e instruir, en la inspección municipal de consumo, los correspondientes procedimientos sancionadores, y remitir los expedientes a la Administración autonómica para que sea ésta, en su caso, quien sancione.

\section{B) Cesión del ejercicio de competencias autonómicas por vía de delegación para ser gestionadas en el ámbito local}

Hay otros supuestos de competencias propias de la Comunidad Autónoma que, sin dejar de serlo, por recaer sobre intereses peculiares de su ámbito, inciden también en el interés local y que, cabalmente por esto, pueden determinar el que la gestión de determinados servicios, actividades y las obras, pudieran considerarse susceptibles de delegación -intersubjetiva- de competencias administrativas. En este caso, por tanto, sin perjuicio de la titularidad autonómica de éstas, el objeto de la cesión al municipio sería el ejercicio de las funciones de gestión que se determinen. Si, por ejemplo, una obra pública de interés regional está justificado que la Comunidad Autónoma la programe, decida su ejecución, etc., nada de ello impide que su gestión pueda asignarse al municipio en cuyo territorio se vaya a realizar ${ }^{55}$.

\footnotetext{
${ }^{55}$ El mecanismo jurídico de la delegación viene previsto en la legislación autonómica murciana desde sus inicios, en el modelo de Administración pública «próxima al ciudadano» que con la Ley 7/1983, de 7 de octubre, se quiso implantar en su ámbito, conforme — según dice en su preámbulo- al principio de descentralización territorial, y siguiendo las directrices marcadas por el Esta-
} 
No sería, sin embargo, a nuestro juicio, correcto técnica ni jurídicamente, delegar funciones de control autonómico en la propia entidad local controlada, que daría lugar a un supuesto de autocontrol, carente de sentido: la descentralización supondría y exigiría en tal caso su supresión para que la actividad se realice por la entidad local a título propio y no como delegada en este caso.

\section{C) La «encomienda» del ejercicio o actuación material de competencias autonómicas a municipios con capacidad de gestión}

Las competencias que usualmente se califican como «encomendadas», en el supuesto de traspaso de funciones que la Administración titular, en nuestro caso la regional, puede asignar a entes locales, pero limitando su objeto a la realización por éstos de funciones de gestión y ejecución material, sin incluir en el objeto de la encomienda facultades resolutivas del ejercicio de la competencia (a diferencia de la delegación), viene previsto y regulado de modo general por la Ley estatal 30/1992, de 26 de noviembre, en su artículo 15, en conexión, en la Región de Murcia, con la Ley autonómica 7/1983, cuyo artículo 17 determina que la Comunidad Autónoma, previa conformidad de la Corporación local que corresponda, podrá facultar a los entes locales para asumir la gestión ordinaria de los servicios propios de la Administración regional, sin que ello suponga delegación del ejercicio de competencias. Igualmente puede utilizarse la organización propia de la entidad local, así como sus oficinas y dependencias para la prestación de los servicios autonómicos. En ambos supuestos, y aquí está la singularidad de esta técnica jurídica, los órganos de la Administración local correspondientes carecen de facultades resolutivas sobre las materias que se les encomienden y los funcionarios que las atiendan han de mantener su dependencia respecto de la Corporación local a la que presten sus servicios, financiando la Comunidad Autónoma los gastos que comporte la colaboración de la entidad local en las actuaciones correspondientes.

D) Fórmulas de gestión paccionada: convenios, consorcios y entes de gestión

La instrumentación jurídica del pacto local también habría de encauzarse, de forma complementaria con otras vías que suponen la voluntad

tuto de Autonomía regional (arts. 18.3 y 23.6). Esta Ley prevé la posibilidad de delegar la Comunidad Autónoma en las Corporaciones locales interesadas «competencias propias» de aquélla siempre que exista «previa conformidad» de la entidad local y, además, ésta tenga capacidad de gestión y medios técnicos suficientes (arts. 4.1, a; 5.1 y 7); normativa ésta que ha de completarse con la básica, y en cuanto tal preferente, de la Ley 7/1985, de régimen local, en su artículo 27. 
autónoma de las partes contratantes en la concertación del acuerdo. La figura de los convenios inter-administrativos, que legalmente pueden concertar la Administración regional y los entes locales, conforme a sus respectivos ordenamientos, y que básicamente cuentan con la cobertura de la Ley 7/1985, de 2 de abril, en sus artículos 57 y 87, supone partir, pues, del principio de voluntariedad en el establecimiento de relaciones de cooperación económica, técnica y administrativa entre ambas Administraciones no sólo respecto a servicios locales, también en asuntos de interés común, como sucede en aquellas materias en las que los municipios pueden realizar actividades complementarias de las propias de la Administración autonómica, para poder gestionar aquéllos asuntos comprendidos en el ámbito de competencias propias, en materias como educación, cultura, sanidad, promoción de la mujer, empleo, etcétera.

La figura del convenio, en cuanto negocio jurídico administrativo de carácter bilateral generado ex voluntate, es plenamente respetuosa con la autonomía de los entes locales y permite, además, lograr una mayor eficacia administrativa y aproximar a los ciudadanos la gestión de asuntos de especial interés común. La problemática de este tipo de convenios entre Administraciones públicas, ha sido convenientemente analizada por la doctrina administrativista ${ }^{56}$, que ha destacado la amplitud de actuaciones susceptibles de amparar el objeto de la cooperación por esta vía. Sin perjuicio del principio de irrenunciabilidad de las competencias propias- que excluye la disposición ex voluntate por vía de convenios normativos de este tipo de competencias por la Administración titular, que limita su transferencia mediante esta técnica convencional, el contenido del convenio puede ser muy amplio: puede servir de cauce para la cesión a entes locales del ejercicio de competencias autonómicas (convenios para la delegación o para la «encomienda» de competencias) y, por ende, para la gestión y ejecución material de determinadas actuaciones, e incluso para llevar a cabo la creación de órganos o de entes de gestión común.

Buen ejemplo de ello nos lo ofrece, pongamos por caso, en materia de urbanismo, la Ley murciana 1/2001, del Suelo, que incluye en su régimen, a los convenios urbanísticos entre la Administración regional y los municipios para facilitar la elaboración del planeamiento urbanístico general de

\footnotetext{
${ }^{56}$ F. Lliset BorRelL: «Los convenios interadministrativos de los entes locales», REDA n. ${ }^{\circ} 47$ (1990), y en Régimen jurídico de las Administraciones Públicas y Procedimiento Administrativo Común (en colaboración con F. Romero Hernández y J. A. López Pellicer, El Consultor, 2000, pp. 63 y sgs.). Asimismo, J. M. Rodríguez Santiago: Los convenios entre Administraciones Públicas, Edit. Marcial Pons, Madrid, 1997.
} 
ordenación municipal (art. 162.2); o en materia de deportes, la gran amplitud de las funciones comprendidas en el ámbito de la competencia municipal, según la Ley autonómica 2/2000, de 12 de julio (art. 9), que incluye la cooperación entre ambas Administraciones, autonómica y local, para la programación y ejecución de instalaciones y actividades que tengan por objeto el cumplimiento de las finalidades legalmente previstas, y cuya cooperación es indudable que podría instrumentarse mediante esta vía convencional.

De otra parte, conviene resaltar que, de las diversas opciones que el ordenamiento jurídico vigente prevé y admite, está también la posibilidad de constituir consorcios ${ }^{57}$. El consorcio implica, como es sabido, la constitución de una nueva entidad administrativa, a la cual se atribuye o encomienda la gestión de determinados servicios o actividades, a realizar por sustitución de las Administraciones consorciadas. Puede abordarse así, de este modo, la gestión unitaria de competencias dispersas, pertenecientes a cada una de las Administraciones integradas en el consorcio. De aquí que la Ley 30/1992 requiera básicamente que en los órganos de decisión de éste han de estar integradas «todas las entidades consorciadas, en la proporción que se fije en los estatutos respectivos», esto es, que las propias entidades integrantes del consorcio tienen la disposición sobre la actividad de éste, con carácter puramente instrumental, para el ejercicio en común de las propias competencias ${ }^{58}$.

\footnotetext{
${ }^{57}$ Artículos 5787 de la Ley 7/1985 y 37 a 40 de Reglamento de Servicios de las Corporaciones Locales de 17 de junio de 1955; y art. 6.5 de la Ley 30/1992 cit. En la doctrina, remito a mi estudio, en la obra Nuevo Régimen Local, Edit. Abella, 2001, I, p. 183 y sgs.; y en colaboración con F. LLISET BorRelL, en nuestros comentarios al citado Reglamento de Servicios Locales, publicados por la misma Editorial, 2001, pp. 249 a 271.

${ }^{58}$ En la legislación autonómica murciana, la Ley 7/1983, de 7 de octubre, establece una regulación de los convenios entre la Administración regional y los entes locales, así como la posible creación de entes de gestión públicos o privados. En su artículo 4.3 se prevé esta posibilidad, abundando así en las previsiones contenidas en la referida normativa estatal básica, al determinar que ambos tipos de Administraciones «podrán formalizar convenios y constituir entes de gestión públicos o privados para la ejecución de obras, explotación de bienes o prestación de servicios determinados que tengan interés local o en los que coincida éste con los regionales, así como instrumentar la asistencia o ayuda a dichas entidades». Convenios que « de modo particular», como dice el artículo 22.1 de esta Ley, pueden suscribirse en materia de «planes y programas de equipamiento del área a que pertenezca la entidad local», así como para la «elaboración y, en su caso, ejecución de estudios, planes y proyectos de actuación comarcal». La especial referencia a estos posibles objetos del convenio, parece indudable que no excluye otras posibles actuaciones, en razón de la no exhaustividad de la relación de supuestos indicados (como cabe deducir de la expresión « de modo particular» que antecede). No es óbice esto a la posibilidad e incluso conveniencia de su explícita ampliación a otros supuestos que especialmente pudieran ser objeto de convenio conforme a las condiciones que pudieran acordarse para hacer efectivo el hipotético pacto local.
} 


\section{Forma de encauzar el proceso de negociación y acuerdo del hipotético pacto local}

Respecto a los actores que han de intervenir y protagonizar éste como partes, cabe considerar que, en razón de la naturaleza fundamentalmente política que el pacto Local tiene, y de sus posibles contenidos y alcance de sus efectos, parece aconsejable que se plantee cuando menos a tres bandas: partidos políticos con representación parlamentaria en la Región — Partido Popular, Partido Socialista Obrero Español e Izquierda Unida, Comunidad Autónoma y Administración local. La intervención de los partidos políticos parece fundamental sobre todo en la inicial determinación de los posibles contenidos, materias y funciones, que hayan de constituir el objeto del posible pacto local, y en el proceso de negociación a través de la representación municipal en el seno de la Federación de Municipios de la Región, que institucionalmente ha de participar, como ya viene haciendo, en representación de los municipios que agrupa, en el procedimiento.

Por el lado de la Comunidad Autónoma, ha de resaltarse el papel asimismo fundamental a cumplir por el Consejo de Gobierno y por su Presidente, en sus funciones de coordinación al mayor nivel del Ejecutivo autonómico, de las actuaciones de las distintas Consejerías y órganos de la Administración regional que pudieran por razón de la materia resultar afectadas por las posibles transferencias. La elaboración de la lista de materias negociable, mediante los trabajos previos a realizar por las distintas Consejerías y órganos sectoriales autonómicos afectados (bajo la coordinación de la Secretaría General de la Presidencia), que posibilite disponer de la documentación necesaria para la negociación que el Pacto supone, así como de las propuestas que se consideren pertinentes, es indudable que permitirían determinar y precisar, desde la perspectiva de la Administración regional, el ámbito de las funciones y servicios susceptibles de descentralización territorial.

La constitución de una Comisión u órgano de composición mixta - paritaria — en la cual se halle representada la Comunidad Autónoma y la Administración local también parece necesaria para servir de cauce institucional a cuyo través se instrumente la gestación y formulación del pacto local, con la determinación, que se acuerde entre ambas partes, de las competencias y funciones asignables a los municipios por alguno de los referidos mecanismos (transferencias, delegaciones, encomiendas de gestión, etc.), que, como es lógico, tendrían que ser considerados en razón de su idoneidad y adecuación respecto del contenido funcional de las competencias a ceder y de la capacidad de gestión de los municipios (además 
de la previsión en paralelo de los recursos económicos que sean necesarios para financiar las correspondientes actuaciones y servicios, cuya determinación habría de hacerse con una metodología valorativa que permita calcular con la debida precisión su coste efectivo y su evolución futura).

La tarea de esta Comisión u órgano mixto se concretaría, en fin, en una propuesta documentada de posibles acuerdos sobre los traspasos de funciones relativas a las distintas materias, y en cuya propuesta convendría determinar los criterios de asignación de funciones, que en unos supuestos pudieran ser uniformes para todos los municipios o bien en otras diversas y condicionadas a la capacidad de gestión local, con aplicación en su caso de fórmulas asociativas o consorciales, etc., que podrían modular así la diversidad de circunstancias concurrentes, en un planteamiento municipalista que no tiene por qué en todo caso simétrico y que, en este sentido, pudiera verse afectado incluso por la regulación que de las grandes ciudades pudiera establecerse en la Ley proyectada para el ámbito estatal, respecto a los municipios que cumplan sus determinaciones.

Por lo demás, formalmente, la propuesta o propuestas de traspasos a los municipios habrá de ser informada — en la Región de Murcia, por el Consejo Regional de Cooperación Local, según establece la Ley autonómica 9/1994, de 30 de diciembre (artículo 3.1, b) —, antes de ser elevada al Consejo de Gobierno autonómico para que, en ejercicio de sus atribuciones, adopte las medidas y disposiciones que en cada caso sean necesarias: así, mediante la formulación de anteproyecto y ulterior aprobación del proyecto de Ley cuando sea necesaria la aprobación de la transferencia en sede parlamentaria, o en otro caso mediante aprobación del decreto o decretos reglamentarios, acuerdos, etc., que fuesen precisos. Quizá fuera conveniente, aunque no sea estrictamente necesario, elaborar un texto legal que contuvieran unas disposiciones generales, referentes a los principios que hayan de regir las transferencias o traspasos, fórmulas y contenidos, completadas con las normas sectoriales que asimismo resultaren necesarias respecto a las distintas materias que sean objeto del pacto local, y que completaran, o modificasen en su caso, las correspondientes Leyes autonómicas preexistentes.

En fin, el desarrollo del texto legal que con posterioridad el Ejecutivo autonómico efectuare en ejercicio de su potestad reglamentaria, de modo general por el Consejo de Gobierno y, en su caso, por cada Consejería afectada, permitiría completar con el detalle que fuera preciso en cada caso el proceso jurídico que el pacto local comporte, en el momento y bajo las condiciones legales que para hacerlo efectivo fueren necesarias. 